\title{
Metal oxalate complexes as novel inorganic dopants: Studies on their effect on conducting polyaniline
}

\author{
R MURUGESAN ${ }^{\dagger}$ and E SUBRAMANIAN* \\ Department of Chemistry, Manonmaniam Sundaranar University, Abishekapatti, Tirunelveli 627 012, India \\ ${ }^{\dagger}$ Deputed on F.I.P. from Department of Chemistry, T.D.M.N.S. College, T. Kallikulam, Tirunelveli 627 113, India
}

MS received 9 July 2001; revised 9 September 2002

\begin{abstract}
Doped polyaniline materials with metal oxalate complexes of $\mathrm{Cr}, \mathrm{Fe}, \mathrm{Mn}, \mathrm{Co}$ and $\mathrm{Al}$ were synthesized by in situ chemical oxidative polymerization of aniline using potassium perdisulphate as oxidant in aqueous sulphuric acid medium. These polymer materials were characterized by chemical analyses, spectral studies (UV-visible and IR), X-ray diffraction and thermal techniques and also by conductivity measurements by four-probe technique. The presence of complex anion in polyaniline material was confirmed by chemical and spectral analyses. The yield and conductivity of metal oxalate doped polyanilines were found to be high when compared to the simple sulphate ion doped polyaniline prepared under similar condition. UV-visible and IR spectral features not only confirmed the polyaniline doping by complex anions but also substantiated their facilitating effect on conductivity. The $\mathrm{X}$-ray diffraction patterns indicated some crystalline nature in metal oxalate doped polyaniline and amorphous in polyaniline sulphate salt. The conductivity of the polymer samples strongly depended on the degree of crystallinity induced by complex counter anions as dopant. All the polymer materials, as evident from TGA curves, were observed to undergo three-step degradation of water loss, de-doping and decomposition of polymer. Further, the thermal stability of polyaniline was found to improve on doping with metal oxalate complex.
\end{abstract}

Keywords. Polyaniline; metal oxalate complex dopant; conductivity; spectral, structural and thermal characterization.

\section{Introduction}

Amongst conducting polymers which have emerged as a new class of materials of current research interest worldwide, polyaniline (Pani) occupies a prominent place owing to its possible wide spread applications (Kuo and Chiou 1997; Gurunathan et al 1999) as compared with other polymers, and also to its unique position in many respects (MacDiarmid et al 1987), especially in possession of amine-imine structural characteristics in its polymer backbone and of protonation dependent doping and conductivity. Many studies (Trivedi 1999) have established that the macromolecular structural, morphological and electrical properties of Pani are found to be dependent on the nature of dopant ion inserted into the polymer. The Bronsted acids are very common dopants (Trivedi 1994) and numerous studies have been conducted on the resulting Pani salt. Organic dopants exhibit favourable features over Bronsted acids with regard to structural and conducting aspects of Pani. For instance, the inclusion of camphorsulphonic acid (Luzny and Banka 2000), p-toluenesulphonic acid (Huang and Wan 1999), or $\beta$-naphthalenesulphonic acid (Wan and $\mathrm{Li}$ 1999) in Pani improves the crystallinity and hence their conductivity. In so far as

\footnotetext{
*Author for correspondence
}

inorganic dopants are concerned, besides mineral acids, studies are very scarce. Recently the heteropolyanions (Barth et al 1999) have been used as dopant for Pani in its electrochemical studies. FeOCl (Hwang et al 1995) and $\mathrm{V}_{2} \mathrm{O}_{5}$ (Huguenin et al 2000) are used in Pani composites for electrode fabrication in rechargeable battery. When Pani is encapsulated into nanoporous aluminosilicate doped with $\mathrm{Cu}^{2+}$ or $\mathrm{Fe}^{3+}$, molecular wires are formed (Luca and Thomson 2000). Lewis inorganic acids such as $\mathrm{ZnCl}_{2}$ (Anand et al 1998), $\mathrm{SnCl}_{4}$ (Kulszewicz-Bajer et al 1999) and $\mathrm{FeCl}_{3}$ (Genoud et al 2000) are the recently investigated dopants. Fusalba and Belanger (1999) have reported a novel inorganic-organic material of Pani with $\mathrm{MoS}_{3}$ dopant. Although inorganic metal complexes bearing negative charge can fulfil the requisites of dopants for Pani, this concept of doping still remains unexploited and studies on this aspect are scarce. Hence in the present work, as a novel approach, we have investigated the doping act of metal oxalate complexes of $\mathrm{Cr}, \mathrm{Fe}, \mathrm{Mn}, \mathrm{Co}$ and $\mathrm{Al}$ and their impact on the structural, electrical and thermal characteristics of Pani.

\section{Experimental}

\subsection{Materials}

All chemicals used were of analytical grade. Aniline [SD 
fine-chem, India] was purified by distillation over zinc dust. Water was used after two distillations. Other chemicals were used as such without any further purification. The following metal oxalate complexes were prepared and purified as per standard methodologies (Palmer 1965; Pass and Sutcliffe 1982): potassium trioxalatochromate (III) [TOCr], potassium trioxalatoferrate (III) [TOFe], potassium trioxalatomanganate (III) [TOMn], potassium trioxalatocobaltate (III) [TOCo] and potassium trioxalatoaluminate (III) [TOAl].

\subsection{Methods}

2.2a Synthesis: Pani and Pani materials with metal oxalate complexes were prepared with $0 \cdot 1 \mathrm{M}$ aniline at room temperature by in situ chemical oxidative polymerization technique using $0 \cdot 1 \mathrm{M}$ potassium perdisulphate [PDS] as oxidant in a manner similar to the described procedure (Trivedi 1997) in sulphuric acid and in a mixture of metal oxalate complex $(100 \mathrm{mg} / 100 \mathrm{ml})$ and sulphuric acid, respectively. Polymerization was effected by drop wise addition of oxidant to the continuously stirred aniline solution for an hour. After addition of PDS, polymerization was allowed to proceed further for overnight in a refrigerator. The precipitate was filtered, washed with distilled water and then with methanol and acetone until the filtrate became colourless and was dried in an air oven at $80^{\circ} \mathrm{C}$ for about $4 \mathrm{~h}$. The dried polymer sample was ground into a fine powder and the yield was noted.

2.2b Chemical analysis: The degree of doping by metal oxalate complex and/or sulphate was determined by chemical methods after leaching them from Pani sample with excess of $2 \mathrm{M}$ aqueous ammonia. Ammonia-Pani mixture was vigorously shaken in a mechanical shaker for about $4 \mathrm{~h}$, kept overnight and then filtered. In this process the metal oxalate complex decomposed into free metal ion and oxalate anion. $\mathrm{SO}_{4}^{2-}$ and $\mathrm{C}_{2} \mathrm{O}_{4}^{2-}$ ions were quantitatively estimated by standard turbidimetric titration (Vogel 1989) (Systronics Digital Nephelo-Turbidity Meter - 132) with $\mathrm{BaCl}_{2}$ reagent and colourimetric method (Pass and Sutcliffe 1982) with acidified permanganate solution as reagent, respectively. Water content of the polymer samples was estimated from the weight changes on drying in a vacuum oven at $130^{\circ} \mathrm{C}$ for about $4 \mathrm{~h}$ until constant weights were noted on repetition.

\subsection{Characterization}

2.3a Conductivity measurement: The powder polymer samples were pressed into pellets of $13 \mathrm{~mm}$ dia and $1 \mathrm{~mm}$ thickness in a hydraulic pellet press (KIMAYA Engineers, India, model WT-324) by maintaining $\sim 3$ ton metric pressure. These pellets were subjected to conductivity measurements in a four-probe set-up (Scientific Equipment and Service, India, model DFP-02). Resistances were determined from the current-voltage behaviour and were converted into conductivity data using the dimensions of the pellet.

2.3b Spectral measurement: UV-visible spectra of all the polymer samples were recorded at room temperature in different solvents viz. $N$-methylpyrrolidone (NMP), dimethyl sulphoxide (DMSO), methanol, acetonitrile and $80 \%(\mathrm{v} / \mathrm{v})$ acetic acid in 330-900 nm range with PerkinElmer UV-visible spectrophotometer (Lambda 3B model) in matched $1 \mathrm{~cm}$ quartz cuvettes. FTIR spectra of polymer samples in $\mathrm{KBr}$ pellets were recorded on a Jasco FTIR 410 spectrophotometer provided with computer software.

2.3c X-ray diffraction and thermal analyses: X-ray diffractograms for all powder polymer samples were obtained using $\mathrm{CuK}_{\alpha}$ radiation $(\lambda=1.5420 \AA)$ on Rigaku instrument (model Miniflex) and thermal studies (TGA and DTG) were carried out from $50^{\circ} \mathrm{C}$ to $800^{\circ} \mathrm{C}$ under air atmosphere with a heating rate of $20^{\circ} \mathrm{C} / \mathrm{min}$ (Perkin Elmer Thermogravimetric Analyser model 7). Both the characterizations were performed at the Catalysis Laboratory, Indian Institute of Technology, Chennai.

\section{Results and discussion}

\subsection{Chemical analyses, yield and conductivity}

Qualitative tests on the filtrate obtained on washing the polymer samples with double distilled water show the absence of any metal ions except $\mathrm{Fe}^{3+}$ and hence indicate the complete incorporation of all the metal oxalates except TOFe into the sample during polymerization. Further, the quantitative analyses described in the experimental part not only confirm their presence but also provide an estimate of their amount in the polymer samples. Table 1 lists all these data together with the yield and conductivity of all the polymer samples. Obviously the ingress of metal oxalate ions affect the yield and conductivity. Generally they show an enhancing yield except for TOFe. This is quite agreeable when one considers the fact that TOFe is a photosensitive compound being used in actinometry. It is likely, therefore, that TOFe would have undergone decomposition during the room light exposed polymerization process. With regard to conductivity also, this enhancing trend continues. Here also the TOFe doped Pani displays a lesser value than Pani- $\mathrm{SO}_{4}^{2-}$ salt, obviously due to the above reason. Additionally $\mathrm{TOCr}$ also shows a declining trend and this is explicable by its increased moisture absorbing tendency. The chemical formula (table 1) deduced by chemical analyses specifies the presence of about 2 water molecules per monomer unit of Pani. TGA data (table 3) also confirm this; TOCr 
doped Pani shows a water weight loss of $16 \%$ while all other samples show only around $11 \%$ weight loss. That the water content in Pani sample is one of the crucial factors affecting conductivity (Travers and Nechtschein 1987; Javedi et al 1988) is a well established fact.

\section{$3.2 U V$-visible spectra}

The observed peak positions of the UV-visible spectra are given in table 2 . In the first three solvents, the samples yield sharp peaks within $360-380 \mathrm{~nm}$ and broad band at $780-820 \mathrm{~nm}$ wavelength ranges. They are ascribed in the previous studies (Koul et al 1997; Patil et al 2000; Rao et al 2000) to the $\pi-\pi^{*}$ exciton band delineating the $\pi$ conjugation and the presence of conducting emeraldine salt, respectively. The observed peaks thus confirm that the prepared sample is in the conducting form containing doped $\mathrm{SO}_{4}^{2-}$ and/or metal oxalate complex. In NMP and DMSO the samples, however, exhibit broad peak around $620 \mathrm{~nm}$ indicating the formation of emeraldine base. Since these two solvents are of coordinating nature, they get coordinated to the protonated $\mathrm{N}$-site after displacing dopant ions and thereby convert salt into base. This observation is also in good agreement with previous reports (Sindhimeshram and Gupta 1995; Rao et al 2000).

\subsection{IR spectra}

Figure 1 illustrates the FTIR spectra of all polymer samples. The principal characteristic peaks of quinoid-benzenoid $\mathrm{N}$ moieties, $\mathrm{C}-\mathrm{N}$ stretching, $\mathrm{C}-\mathrm{H}$ aromatic in-plane and out-plane bending vibrations of Pani are reported to occur at about 1600, 1500, 1350, 1130 and $820 \mathrm{~cm}^{-1}$, respectively (Boyer et al 1998). In the present study also, all these peaks are observed in $\mathrm{Pani}-\mathrm{SO}_{4}^{2-}$ (figure 1, curve 1) but are modified both in intensity and peak position on doping with metal oxalate complexes (figure 1, curves 2-6). These changes clearly indicate the structural and chemical modifications of Pani by metal oxalate complex dopants. For example, the intensity of $\mathrm{C}-\mathrm{N}^{\oplus}$ stretching doublet band (1350-1380 $\mathrm{cm}^{-1}$ ) (Athawale et al 1999) is enhanced very much relative to others on doping with complex ion than with $\mathrm{SO}_{4}^{2-}$ alone (compare spectrum 1 with others). Moreover, in $\mathrm{Cr}, \mathrm{Mn}$ and $\mathrm{Al}$ oxalate doped Pani materials, this doublet splits into a triplet and shifts to lower wavenumber, $1300 \mathrm{~cm}^{-1}$. This observation demonstrates that in Pani materials, the $\mathrm{C}-\mathrm{N}$ group vibration is facilitated much, possibly due to its greater promotion and/or degree of exposure. Boyer et al (1998) have made a similar observation and attributed it to polymer chain length increase; in fact they have treated this band as a diagnostic of chain length. Therefore, in our case, since

Table 1. Yield, conductivity and chemical analyses data of polyaniline samples.

\begin{tabular}{|c|c|c|c|c|c|c|}
\hline \multirow[b]{2}{*}{ Sample } & \multirow{2}{*}{$\begin{array}{l}\text { Yield } \\
(\mathrm{mg})\end{array}$} & \multirow{2}{*}{$\begin{array}{l}\text { Yield } \\
(\%)\end{array}$} & \multirow{2}{*}{$\begin{array}{c}\text { Specific } \\
\text { conductivity } \\
(\mathrm{S} / \mathrm{cm})\end{array}$} & \multicolumn{2}{|c|}{ Dopant ions (\%) (w/w) } & \multirow{2}{*}{$\begin{array}{l}\text { Chemical formula based on } \\
\text { aniline monomer unit }\end{array}$} \\
\hline & & & & $\mathrm{SO}_{4}^{2-}$ & Metal oxalate & \\
\hline Pani-SO $\mathrm{SO}_{4}^{2-}$ & 560 & $60 \cdot 2$ & $1 \cdot 24$ & $36 \cdot 2$ & - & $\mathrm{C}_{6} \mathrm{H}_{5} \mathrm{~N}\left(\mathrm{SO}_{4}^{2-}\right)_{0.69} 1 \cdot 4 \mathrm{H}_{2} \mathrm{O}$ \\
\hline Pani-SO ${ }_{4}^{2-} / \mathrm{TOCr}$ & 618 & $66 \cdot 5$ & $1 \cdot 06$ & $37 \cdot 4$ & $11 \cdot 5$ & $\mathrm{C}_{6} \mathrm{H}_{5} \mathrm{~N}\left(\mathrm{SO}_{4}^{2-}\right)_{0.95}(\mathrm{TOCr})_{0.09} 1.9 \mathrm{H}_{2} \mathrm{O}$ \\
\hline Pani-SO ${ }_{4}^{2-} / \mathrm{TOFe}$ & 559 & $60 \cdot 1$ & $0 \cdot 61$ & $22 \cdot 2$ & $10 \cdot 5$ & $\mathrm{C}_{6} \mathrm{H}_{5} \mathrm{~N}\left(\mathrm{SO}_{4}^{2-}\right)_{0.38}(\mathrm{TOFe})_{0.05} 1 \cdot 0 \mathrm{H}_{2} \mathrm{O}$ \\
\hline Pani-SO ${ }_{4}^{2-} / \mathrm{TOMn}$ & 635 & $68 \cdot 3$ & $4 \cdot 17$ & $36 \cdot 8$ & $10 \cdot 2$ & $\mathrm{C}_{6} \mathrm{H}_{5} \mathrm{~N}\left(\mathrm{SO}_{4}^{2-}\right)_{0.77}(\mathrm{TOMn})_{0.06} 0.89 \mathrm{H}_{2} \mathrm{O}$ \\
\hline Pani-SO ${ }_{4}^{2-} / \mathrm{TOCo}$ & 589 & $63 \cdot 3$ & $2 \cdot 31$ & $31 \cdot 0$ & $10 \cdot 6$ & $\mathrm{C}_{6} \mathrm{H}_{5} \mathrm{~N}\left(\mathrm{SO}_{4}^{2-}\right)_{0.61}(\mathrm{TOCo})_{0.06} 1 \cdot 0 \mathrm{H}_{2} \mathrm{O}$ \\
\hline Pani-SO ${ }_{4}^{2-} / \mathrm{TOAl}$ & 629 & $67 \cdot 6$ & $6 \cdot 50$ & $36 \cdot 5$ & $10 \cdot 4$ & $\mathrm{C}_{6} \mathrm{H}_{5} \mathrm{~N}\left(\mathrm{SO}_{4}^{2-}\right)_{0.77}(\mathrm{TOAl})_{0.07} 0.89 \mathrm{H}_{2} \mathrm{O}$ \\
\hline
\end{tabular}

Table 2. UV-visible absorption data of polyaniline samples in various solvents.

\begin{tabular}{|c|c|c|c|c|c|c|c|c|c|c|c|c|c|}
\hline \multirow{3}{*}{$\frac{\text { Sample }}{\text { Pani-SO }}$} & \multicolumn{13}{|c|}{ Peak position (nm) } \\
\hline & \multicolumn{3}{|c|}{$80 \%(\mathrm{v} / \mathrm{v})$ acetic acid } & \multicolumn{3}{|c|}{ Methanol } & \multicolumn{2}{|c|}{ Acetonitrile } & \multicolumn{2}{|c|}{ NMP } & \multicolumn{3}{|c|}{ DMSO } \\
\hline & 382 & 546 & & 367 & & 808 & 369 & 805 & & 628 & & 608 & 798 \\
\hline Pani-SO ${ }_{4}^{2-} / \mathrm{TOCr}$ & 378 & & 740 & 367 & & 807 & 367 & 808 & & 631 & 366 & 630 & \\
\hline Pani-SO ${ }_{4}^{2-} / \mathrm{TOFe}$ & 379 & 579 & 790 & 367 & & 789 & 365 & 804 & 349 & 604 & & 639 & 797 \\
\hline Pani-SO ${ }_{4}^{2-} / \mathrm{TOMn}$ & 383 & & 782 & 368 & & 810 & 370 & 802 & & 630 & 351 & 685 & 811 \\
\hline Pani-SO ${ }_{4}^{2-} / \mathrm{TOCo}$ & 377 & 557 & 802 & 364 & 525 & 795 & 364 & 801 & & 624 & & 621 & 817 \\
\hline Pani-SO ${ }_{4}^{2-} / \mathrm{TOAl}$ & 379 & 479 & 802 & 367 & 652 & 807 & 367 & 803 & 332 & 629 & & 693 & 812 \\
\hline
\end{tabular}


Table 3. XRD data of polyaniline samples.

\begin{tabular}{|c|c|c|}
\hline Sample & $2 \theta\left(^{\circ}\right)$ & $d$-space $(\AA)$ \\
\hline Pani-SO $\mathrm{SO}_{4}^{2-}$ & $24 \cdot 0$ & $3 \cdot 708$ \\
\hline Pani-SO ${ }_{4}^{2-} / \mathrm{TOCr}$ & $21 \cdot 5$ & $4 \cdot 135$ \\
\hline Pani-SO ${ }_{4}^{2-} / \mathrm{TOFe}$ & $22 \cdot 0$ & $4 \cdot 041$ \\
\hline $\mathrm{Pani}-\mathrm{SO}_{4}^{2-} / \mathrm{TOMn}$ & $21 \cdot 5$ & $4 \cdot 135$ \\
\hline Pani-SO ${ }_{4}^{2-} / \mathrm{TOCo}$ & 21.7 & $4 \cdot 096$ \\
\hline Pani-SO ${ }_{4}^{2-} / \mathrm{TOAl}$ & $21 \cdot 5$ & $4 \cdot 135$ \\
\hline
\end{tabular}

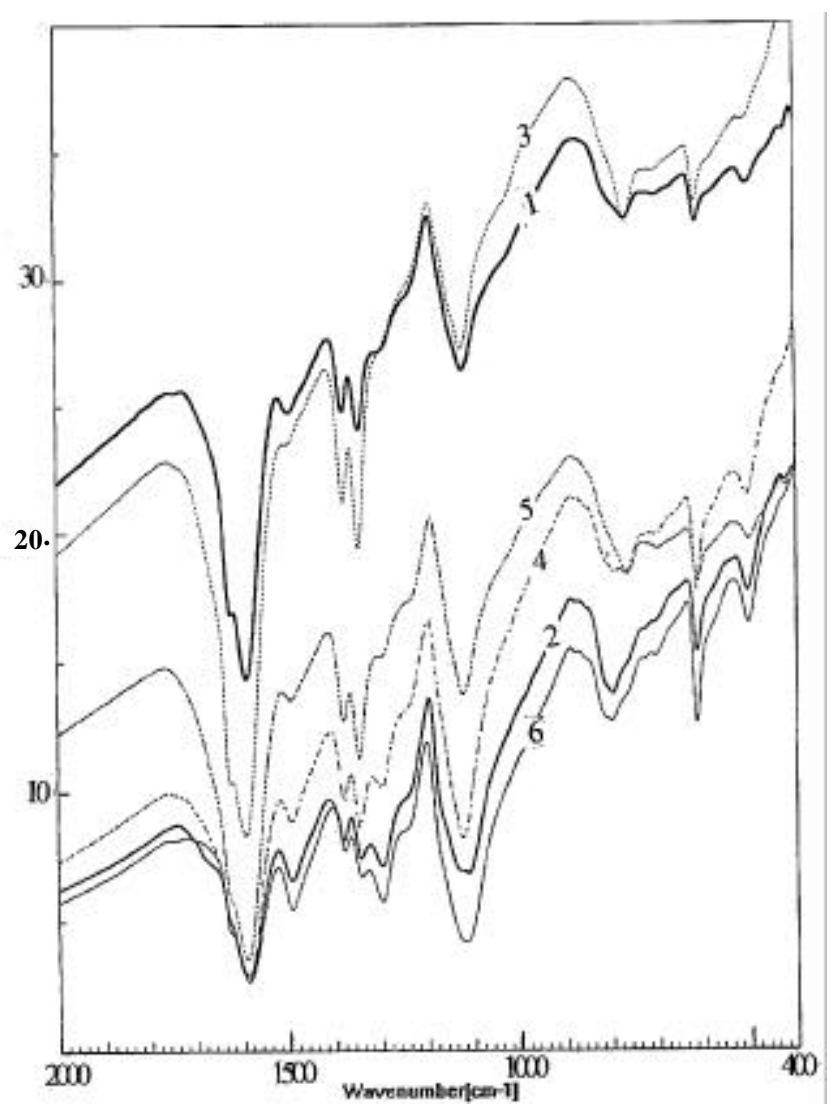

Figure 1. FTIR spectra of polyaniline samples (1. Pani- $\mathrm{SO}_{4}^{2-}$; 2. Pani-SO ${ }_{4}^{2-} / \mathrm{TOCr}$; 3. Pani-SO ${ }_{4}^{2-} / \mathrm{TOFe}$; 4 . Pani-SO ${ }_{4}^{2-} / \mathrm{TOMn}$; 5. Pani-SO $\mathrm{SO}_{4}^{2-} / \mathrm{TOCo} ; 6$. Pani-SO $\mathrm{SO}_{4}^{2-} / \mathrm{TOAl}$ ).

the complex ions are of greater negativity and larger size than $\mathrm{SO}_{4}^{2-}$, their inclusion in and strong interaction with Pani may create additional $\mathrm{C}-\mathrm{N}^{\oplus}$ groups (structural change) or as suggested by Boyer et al it may enhance the polymer chain length (conformational change) leading to exposure of the hidden $\mathrm{C}-\mathrm{N}^{\oplus}$ groups. Previous works (Genies and Laprowaski 1987; Harada et al 1989; Ray et al 1990) have noted that the relative concentration of various $\mathrm{N}$ moieties: $\mathrm{NH},{ }^{\oplus} \mathrm{NH}_{2}, \mathrm{~N}=,{ }^{\oplus} \mathrm{NH}=, \mathrm{C}=\mathrm{N}^{\oplus}-$ in Pani depends on the nature and percent of doping which in turn may affect the population of charge defect centres (polaron and bipolaron) and ultimately the electrical conductivity. Coinciding with this fact, in the present work also a fair agreement between conductivity and intensity of IR spectra is observed.

One more spectral observation also supports the above interpretation. The charge delocalization peaks appearing at $\sim 1125$ and $616 \mathrm{~cm}^{-1}$ which have direct correlation with conductivity (Koul et al 1997; Athawale et al 1999; Zhao et al 2000) also show pronounced intensity in Pani materials on comparison with those in Pani- $\mathrm{SO}_{4}^{2-}$ and Pani-TOFe samples. This suggests a greater $\pi$-electron delocalization in Pani materials and thereby explains the enhanced conductivity.

\section{$3.4 \quad X$-ray diffraction studies}

Powder X-ray diffraction results of polymer samples are given in table 3 . The patterns do not show any sharp peak and suggest generally an amorphous nature to all the polymer samples. However, the polymer samples display diffuse broad peak at $2 \theta$ ranging from $20^{\circ}$ to $25^{\circ}$. The $d$ spacing was calculated from the $2 \theta$ value (table 3 ) and is reported to be the characteristic distance between the ring planes of benzene ring in adjacent chains and is also said to be the interchain distance or the close contact distance between two adjacent chains (Borkar and Gupta 1990). Further, it is a general observation that the polymer chain array and interchain distance are affected by the size and shape of the interlying dopants which results in an increase in electron delocalization length when the dopants are of large size (Pouget et al 1995). The $d$-spacing values are higher in all Pani materials as compared with Pani- $\mathrm{SO}_{4}^{2-}$ salt. Since the metal oxalate dopant has larger size than $\mathrm{SO}_{4}^{2-}$, its inclusion is more probable to increase the interchain distance and consequently the charge delocalization length. This is a very crucial and favourable factor to have higher conductivity value.

\subsection{Thermal studies}

Table 4 presents the thermogravimetric analysis results of all polymer samples. All the polymer samples undergo three-step degradation of (i) loss of water molecules, (ii) de-doping of $\mathrm{SO}_{4}^{2-}$ and metal oxalate complex and (iii) decomposition of polymer material. Pani-TOCr material unlike others has one sharp inflection in DTG which occurs due to the rapid decomposition of polymer material in $400-620^{\circ} \mathrm{C}$ range. Moreover, in this case the water content is high and perhaps this factor may be responsible for its abnormal behaviour. For other Pani materials and $\mathrm{Pani}-\mathrm{SO}_{4}^{2-}$ salt, the decomposition of polymer is slow and takes place in $500-800^{\circ} \mathrm{C}$. A remarkable feature of Pani materials which is absent in Pani- $\mathrm{SO}_{4}^{2-}$ salt is that they leave behind a little amount of residue even after complete degradation, and this may be 
Table 4. TGA and DTG data of polyaniline samples.

\begin{tabular}{|c|c|c|c|c|c|c|}
\hline \multirow{2}{*}{$\frac{\text { Sample }}{\text { Pani-SO }}$} & \multirow{2}{*}{$\begin{array}{c}\text { Temperature } \\
\text { range }\left({ }^{\circ} \mathrm{C}\right)\end{array}$} & \multirow{2}{*}{$\begin{array}{c}\text { Weight loss } \\
(\%) \\
11 \cdot 0 \\
52 \cdot 0 \\
99 \cdot 0 \\
-\end{array}$} & \multirow{2}{*}{$\begin{array}{c}\begin{array}{c}\text { Residue } \\
(\%)\end{array} \\
\begin{array}{c}\text { No } \\
\text { residue }\end{array}\end{array}$} & \multicolumn{2}{|c|}{$\begin{array}{l}\text { DTG peaks } \\
\quad\left(\mathrm{T}^{\circ} \mathrm{C}\right)\end{array}$} & \multirow{2}{*}{$\begin{array}{l}\text { Comments } \\
\begin{array}{l}\text { Decomposition is completed by } 770^{\circ} \mathrm{C} \text { with two } \\
\text { broad inflection points }\end{array}\end{array}$} \\
\hline & & & & 286 & 675 & \\
\hline Pani-SO ${ }_{4}^{2-} / \mathrm{TOCr}$ & $\begin{array}{c}50-200 \\
200-400 \\
400-620 \\
\text { above } 800\end{array}$ & $\begin{array}{c}16 \cdot 0 \\
62 \cdot 0 \\
96 \cdot 0 \\
-\end{array}$ & $1 \cdot 68$ & 515 & & $\begin{array}{l}\text { Decomposition is completed by } 620^{\circ} \mathrm{C} \text { leaving a } \\
\text { little residue with one sharp inflection point }\end{array}$ \\
\hline Pani-SO ${ }_{4}^{2-} / \mathrm{TOFe}$ & $\begin{array}{c}50-255 \\
255-490 \\
490-720 \\
\text { above } 800\end{array}$ & $\begin{array}{l}12 \cdot 0 \\
44 \cdot 0 \\
98 \cdot 0 \\
-\end{array}$ & $1 \cdot 53$ & 300 & 596 & $\begin{array}{l}\text { Decomposition is completed by } 720^{\circ} \mathrm{C} \text { with a } \\
\text { little residue with two broad inflection points }\end{array}$ \\
\hline Pani-SO ${ }_{4}^{2-} / \mathrm{TOMn}$ & $\begin{array}{c}50-210 \\
210-500 \\
500-800 \\
\text { above } 800\end{array}$ & $\begin{array}{l}11 \cdot 0 \\
53 \cdot 0 \\
94 \cdot 0 \\
-\end{array}$ & $4 \cdot 70$ & 298 & & $\begin{array}{l}\text { Decomposition is completed by } 800^{\circ} \mathrm{C} \text { leaving } \\
5 \% \text { residue with one sharp inflection point }\end{array}$ \\
\hline Pani- $\mathrm{SO}_{4}^{2-} / \mathrm{TOCo}$ & $\begin{array}{c}50-210 \\
210-550 \\
550-800 \\
\text { above } 800\end{array}$ & $\begin{array}{l}12 \cdot 0 \\
58 \cdot 0 \\
91 \cdot 0 \\
-\end{array}$ & $8 \cdot 33$ & 290 & & $\begin{array}{l}\text { Decomposition is completed by } 800^{\circ} \mathrm{C} \text { leaving } \\
8.5 \% \text { residue with one sharp inflection point }\end{array}$ \\
\hline Pani- $\mathrm{SO}_{4}^{2-} / \mathrm{TOAl}$ & $\begin{array}{c}50-220 \\
220-500 \\
500-800 \\
\text { above } 800\end{array}$ & $\begin{array}{l}11 \cdot 0 \\
60 \cdot 0 \\
93 \cdot 0 \\
-\end{array}$ & $5 \cdot 50$ & 295 & & $\begin{array}{l}\text { Decomposition is completed by } 800^{\circ} \mathrm{C} \text { leaving } \\
6 \% \text { residue with one sharp inflection point }\end{array}$ \\
\hline
\end{tabular}

the metal oxide which is undegradable at $800^{\circ} \mathrm{C}$. Conclusively the TGA studies point out the inference that Pani materials, excepting those of $\mathrm{TOCr}$ and TOFe for their obvious reasons, are thermally more stable than Pani- $\mathrm{SO}_{4}^{2-}$ salt.

\section{Conclusions}

Generally polyanilines as synthesized are macromolecular cations and for charge compensation they take up counter ions from the reactant mixture or electrolyte. Thus the electrical conductivity, thermal stability, structural properties and processability have been reported to be a function of counter ions which could be explained in terms of electronegativity, molecular charge, molecular size, orientation and solvation (Trivedi 1997). Among the five metal oxalate complexes investigated in the present work, those of $\mathrm{Al}, \mathrm{Mn}$ and $\mathrm{Co}$ on doping into Pani improve the polymerization yield, conductivity and thermal stability of polymer material, perhaps through their large molecular size, efficient electron transfer and the consequent charge transport mechanism and support for crystallinity. Electronic and IR spectral features provide evidences in favour of their dopant role. The present work, therefore, unequivocally brings to light that anionic metal oxalate complexes could be regarded as better novel inorganic dopants for organic conductive polymers.

\section{Acknowledgement}

The financial assistance offered by UGC in the form of minor project and teacher fellowship to (RM) is gratefully acknowledged.

\section{References}

Anand J, Rao P S, Palaniappan S and Sathiyanarayana D N 1998 Changes in the electronic properties of polyaniline$\mathrm{HCl}$ salt and base induced by $\mathrm{ZnCl}_{2}$, in Macromolecules new frontiers (ed.) K S V Srinivasan (New Delhi: Allied Publishers Ltd) Vol. 1, p. 371

Athawale A A, Deore B A and Kulkarni M V 1999 Mater. Chem. Phys. 60262

Barth M, Lapkowski M and Lefrant S 1999 Electrochim. Acta 442117

Borkar A D and Gupta M C 1990 Indian J. Chem. A29 631

Boyer M I, Quillard S, Rebourt E, Louarn G, Bulsson J P, Monkman and Lefrant S 1998 J. Phys. Chem. B102 7382

Fusalba F and Belanger D 1999 J. Mater. Res. 141805

Genies E M and Laprowaski M 1987 Synth. Met. 21117

Genoud F, Kulszewicz-Bajer I, Bedel A, Oddou J L, Jeandey C and Pron A 2000 Chem. Mater. 12744

Gurunathan K, Murugan A V, Marimuthu R, Mulik U P and Amalnerkar D P 1999 Mater. Chem. Phys. 61173

Harada I, Furukawa Y and Ueda F 1989 Synth. Met. 29 E303

Huang J and Wan M X 1999 J. Polym. Sci. A-Polym. Chem. 37 1277 
Huguenin F, Gambardella M T P, Torresi R M, Torresi S I C and Buttry D A 2000 J. Electrochem. Soc. 1472437

Hwang K S, Kim J S and Kong M J 1995 Synth. Met. 712201

Javedi H H S, Angelopoulos M, MacDiarmid A G and Epstein A J 1988 Synth. Met. 261

Koul S, Dhawan S K and Chandra S 1997 Indian J. Chem. A36 901

Kulszewicz-Bajer I, Pron A, Abramowicz J, Jeandey C, Oddou J L and Sobczak J 1999 Chem. Mater. 11552

Kuo C T and Chiou W H 1997 Synth. Met. 8823

Luca V and Thomson S 2000 J. Mater. Chem. 102121

Luzny W and Banka E 2000 Macromol. 33425

MacDiarmid A G, Chiang J C, Richte A F and Epstein A J 1987 Synth. Met. 18285

Palmer W G 1965 Experimental inorganic chemistry (Cambridge: Cambridge University Press) p. 521

Pass G and Sutcliffe H 1982 Practical inorganic chemistry (New York: Chapman and Hall Ltd) 2nd ed.

Patil R C, Patil S F, Mulla I S and Vijayamohanan K 2000 Polym. Int. 49189

Pouget J P, Hsu C H, MacDiarmid A G and Epstein A J 1995 Synth. Met. 69119
Rao P S, Anand J, Palaniappan S and Sathyanarayana D N 2000 Eur. Polym. J. 36915

Ray A, MacDiarmid A G, Ginder J M and Epstein A J 1990 Mater. Res. Soc. Symp. Proc. 173353

Sindhimeshram D C and Gupta M C 1995 Indian J. Chem. A34 260

Travers J P and Nechtschein M 1987 Synth. Met. 21135

Trivedi D C 1994 Indian J. Chem. A33 552

Trivedi D C 1997 Polyanilines, in Conductive molecules and electric properties, Handbook of organic conductive molecules and polymers (ed.) H S Nalwa (Chichester: John Wiley and Sons Ltd) Vol. 2, p. 505

Trivedi D C 1999 Bull. Mater. Sci. 22447

Vogel A I 1989 Text book of quantitative chemical analysis (Revised) (eds) G H Jeffery, J Bassett, J Mendham and R C Denney (London: ELBS with Longman Group UK Ltd) 5th ed., p. 729

Wan M X and Li J C 1999 J. Polym. Sci. A-Polym. Chem. 37 4605

Zhao B, Neoh K G and Kang E T 2000 Chem. Mater. 12 1800 